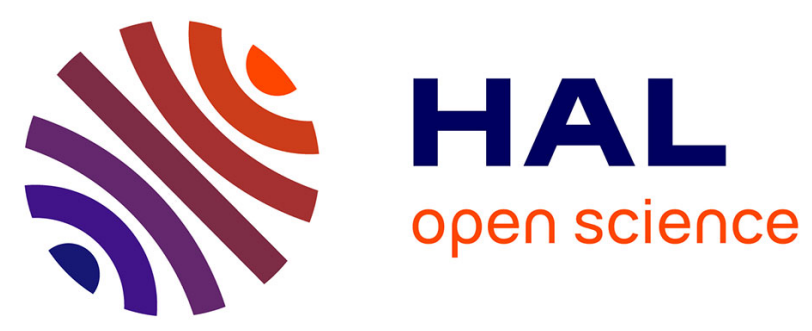

\title{
Luminescence properties of micrometric structures induced by direct laser writing in silver containing phosphate glass
}

Kevin Bourhis, Arnaud Royon, Gautier Papon, Lionel Canioni, N. Makria, Yannick Petit, Thierry Cardinal

\section{To cite this version:}

Kevin Bourhis, Arnaud Royon, Gautier Papon, Lionel Canioni, N. Makria, et al.. Luminescence properties of micrometric structures induced by direct laser writing in silver containing phosphate glass. Journal of Non-Crystalline Solids, 2013, 377, pp.142-145. 10.1016/j.jnoncrysol.2013.01.041 . hal-00870643

\section{HAL Id: hal-00870643 \\ https://hal.science/hal-00870643}

Submitted on 28 Feb 2018

HAL is a multi-disciplinary open access archive for the deposit and dissemination of scientific research documents, whether they are published or not. The documents may come from teaching and research institutions in France or abroad, or from public or private research centers.
L'archive ouverte pluridisciplinaire HAL, est destinée au dépôt et à la diffusion de documents scientifiques de niveau recherche, publiés ou non, émanant des établissements d'enseignement et de recherche français ou étrangers, des laboratoires publics ou privés.

\section{()ㅜ(1)}

Distributed under a Creative Commons Attribution - NonCommerciall 4.0 International 


\title{
Luminescence properties of micrometric structures induced by direct laser writing in silver containing phosphate glass
}

\author{
K. Bourhis ${ }^{\mathrm{a}, \mathrm{b}}$, A. Royon ${ }^{\mathrm{c}}$, G. Papon ${ }^{\mathrm{c}}$, L. Canioni ${ }^{\mathrm{c}}$, N. Makria ${ }^{\mathrm{a}, \mathrm{b}}$, Y. Petit $^{\mathrm{a}, \mathrm{b}}$, T. Cardinal $^{\mathrm{a}, \mathrm{b}, *}$ \\ a CNRS, ICMCB, UPR 9048, F-33600 Pessac, France \\ ${ }^{\mathrm{b}}$ Univ. Bordeaux, ICMCB, UPR 9048, F-33600 Pessac, France \\ c Univ. Bordeaux, LOMA, UMR 5798, F-33400 Talence, France
}

\section{A R T I C L E I N F O}

Keywords:

phosphate glass;

direct laser writing;

cluster;

luminescence;

nonlinear absorption

\begin{abstract}
A B S T R A C T
Luminescent structures have been implemented by direct laser writing using high repetition rate femtosec ond laser in a silver ion containing photosensitive glass. The optical and luminescence properties have been investigated and compared to those measured after irradiation by a nanosecond laser followed by a thermal treatment. Analogous signals were obtained, demonstrating that the femtosecond direct laser writing com bines in one single operation both a photomodification of the silver oxidation states, and a strong local concentration of silver clusters thanks to the high repetition rate. The comparative study confirms the remarkable stability of the photo induced species with respect to the temperature.
\end{abstract}

\section{Introduction}

Ultra short pulsed lasers, e.g. femtosecond (fs) lasers, have been demonstrated since more than 10 years to be powerful tools for sur face and in depth modification of transparent materials [1,2]. The high spatial precision of these induced modifications has allowed for the fabrication of three dimensional (3D) micro optical devices and photonic structures, such as micro lenses [3], optical memories [4,5], waveguides [6,7], or optical filters [1]. High repetition rate $(>200 \mathrm{kHz})$ ultra short laser pulses cause heat accumulation effects [8]. Thermal energy is generally considered as a negative factor for precise laser processing, because the heat diffusion enlarges the mod ified volume. The influence of the temperature has been investigated by Shimizu et al., who related the size of fs laser induced ring struc tures presenting a high refractive index change to the local tempera ture gradient [9]. However the thermal effects may be considered as positive for activating ionic migration or for allowing phase separa tion mechanisms [2]. The local precipitation of crystals within the glass [10] or the modification of the chemical composition distribution around the laser focal volume [11,12] can be monitored to control the physico chemical properties in glass in 3D. Most of the time, the modi fication takes place on a micrometric scale. Developing new composite materials with innovating functions is the current big challenge of fs

\footnotetext{
* Corresponding author at: CNRS, ICMCB, UPR 9048, F-33600 Pessac, France. Tel.: + 335 400025 43; fax: + 33540002761 .

E-mail address: cardinal@icmcb-bordeaux.cnrs.fr (T. Cardinal).
}

laser structuring. One path is to introduce photosensitive ions inside the glass in which optical properties can be tailored by the interaction with the fs laser [2].

Recently our group showed that near infrared (NIR) fs laser struc turing in silver ions containing photosensitive glass at a 1 to $10 \mathrm{MHz}$ repetition rate resulted in fluorescent pipes without any significant variation of the refractive index $\left(\Delta n<10^{-4}\right)[13,14]$. The section of the pipes is organized as a ring structure. The photo chemical reac tions leading to the formation of highly fluorescent silver clusters are initiated by free electrons generated through multi photon ab sorption and activated by the thermal effects [15]. The proposed model for the fluorescent ring shaped formation [14] strongly suggested that threshold effects were mostly responsible of the spa tial distribution of the silver clusters. A 3D control of the fluorescence intensity of silver clusters was achieved by controlling the NIR fs laser parameters [16]. We showed that the emission spectra are dependant on the irradiation conditions. However the influence of the tempera ture on the formation of the photo induced silver species is still under debate. The major difficulty is to separate the thermal effects from modifications induced by the radiation absorption. The characteriza tion of the luminescence properties is not an easy task since the af fected zone has sub micrometric dimensions.

In this study, the absorption and luminescence properties of the photo induced structures are investigated using an adapted irradia tion protocol in order to access to the luminescence properties. The goal of the study is to compare the optical signatures (absorption and luminescence) of the glass after fs or nanosecond (ns) laser irra diation followed or not by a heat treatment. The effect and the role of hole and electron traps as well as those of the temperature on the 
formation of the photo induced luminescent structures in both irradi ation regimes are discussed.

\section{Experimental section}

Glasses with the composition $40 \mathrm{P}_{2} \mathrm{O}_{5} \quad 55 \mathrm{ZnO} \quad 1 \mathrm{Ga}_{2} \mathrm{O}_{3} \quad 4 \mathrm{Ag}_{2} \mathrm{O}$ (mol\%) were prepared by melt quenching as previously described in $[14,15]$. The pristine glass exhibits an emission band at around $370 \mathrm{~nm}$ for an excitation band centered at $260 \mathrm{~nm}$.

A Yb:KGW 500 fs ultrafast laser (t pulse 500, Amplitude Systemes) operating at $1030 \mathrm{~nm}$ with a repetition rate of $10 \mathrm{MHz}$ and a maximum pulse energy of $600 \mathrm{~nJ}$ was used for the irradiation. The laser mode is $\mathrm{TEM}_{00}$ with $\mathrm{M}^{2}=1.2$. The laser beam was focused with a microscope objective $(\mathrm{NA}=0.75)$ into the glass sample mounted on a computer controlled 3D translational stage with a $10 \mathrm{~nm}$ resolution. The local structuring mechanisms of the photosensitive silver containing glass have been described elsewhere $[14,16]$. The photo induced structure has a cylindrical shape, in which the walls are composed of photo produced luminescent species (Fig. 1a) [14,15]. The displacement of the sample along a transverse direction leads to the writing of parallel luminescent planes, in the longitudinal direction, since the center of the Gaussian beam erases the structure and its edges maintain the lumi nescent features (Fig. 1b) [16]. Parallel structures have been written to obtain an area of $400 \times 400 \mu \mathrm{m}^{2}$ perpendicular to the propagation axis and formed of parallel planes. A stage velocity of $100 \mu \mathrm{m} \cdot \mathrm{s}^{-1}$ has been used with an irradiance of $6 \mathrm{TW} \cdot \mathrm{cm}^{-2}$.

The transmission spectra were collected on a $50 \times 50 \mu^{2}$ area of the "squared" pattern. The micro transmission spectra were collected using a CRAIC micro spectrometer equipped with a Xe lamp, a mono chromator and a CCD detector. The spectral resolution was $0.7 \mathrm{~nm}$. The reference transmission spectrum has been collected on a virgin area of the glass.

Glass samples were also exposed to a UV ns laser emitting at $355 \mathrm{~nm}$ (a mode locked Nd:YAG laser Surelite Continuum L10 equipped with $\mathrm{BBO}$ nonlinear crystals) pumped by flash lamps. The pulse dura tion was $57 \mathrm{~ns}$ at a $10 \mathrm{~Hz}$ repetition rate for an $80 \mathrm{~mJ}$ pulse energy. The beam diameter on the glass sample was $5 \mathrm{~mm}$. The fluence was $320 \mathrm{~J} \cdot \mathrm{cm}^{-2}$ and the irradiance $67 \mathrm{MW} \cdot \mathrm{cm}^{-2}$. The absorption spectra were measured on $2 \mathrm{~mm}$ thick samples with a double beam spectro photometer (CARY 5000 UV VIS) over the $200800 \mathrm{~nm}$ spectral range. A heat treatment at $400{ }^{\circ} \mathrm{C}$ during $10 \mathrm{~min}$ was conducted after the ns laser irradiation.

The luminescence spectra (emission and excitation) on the fs and ns irradiated glasses were recorded on a SPEX Fluorolog 2 spectroflu orimeter (Horiba Jobin Yvon). The excitation source was a $450 \mathrm{~W}$ Xe lamp enabling continuous excitation from $200 \mathrm{~nm}$ to $800 \mathrm{~nm}$. The signal was detected and amplified by a Hamamatsu R298 photo multiplier tube cooled by Peltier effect.

\section{Results}

The transmission spectra of the "squared" pattern written by fs laser are reported in Fig. 2a. Two intense absorption bands peaking at $285 \mathrm{~nm}$ and $325 \mathrm{~nm}$ can be observed. A long tail of the absorption is no ticed above $330 \mathrm{~nm}$ showing that absorption features are present up to $500 \mathrm{~nm}$. The strongest absorption band at around $325 \mathrm{~nm}$ leads to a transmission value of around $50 \%$, which underlines the strong absorb ing character of the photo induced pattern. The lines do not fully fill the entire plane and the height of the structure is estimated to be $7 \mu \mathrm{m}$ FWHM. It means that the absorption coefficient associated to the struc ture is high enough to absorb most of the incident light. The photo induced structures exhibit an intense white emission under excitation at $325 \mathrm{~nm}$, as shown in Fig. 2b. The emission band maximum is centered at $525 \mathrm{~nm}$, accompanied by an intense shoulder at around $400 \mathrm{~nm}$. The excitation spectra for the emission at $700 \mathrm{~nm}$ give rise to two main bands (Fig. 2b) at $275 \mathrm{~nm}$ and $325 \mathrm{~nm}$, with a shoulder around $260 \mathrm{~nm}$.

Fig. 3a presents the absorption spectra of the virgin glass and the glass after UV ns laser irradiation, followed or not by a heat treatment at $400{ }^{\circ} \mathrm{C}$ for $10 \mathrm{~min}$. In both cases, three intense absorption bands are present at around $285 \mathrm{~nm}, 325 \mathrm{~nm}$ and $380 \mathrm{~nm}$. After the heat treat ment, the intensity of these bands is strongly reduced. Absorption features can only be distinguished below $360 \mathrm{~nm}$. For an excitation at $325 \mathrm{~nm}$, the ns irradiated zone presents a red luminescence with a maximum at $630 \mathrm{~nm}$ and a shoulder at $450 \mathrm{~nm}$ (Fig. 3b). The heat treat ment strongly modifies the emission spectrum with a strong decrease of the main band at $630 \mathrm{~nm}$, accompanied by the increase of the band at around $500 \mathrm{~nm}$ and the appearing of a band at around $400 \mathrm{~nm}$. The excitation spectra before heat treatment, for an emission wavelength at $700 \mathrm{~nm}$, present excitation bands at $275 \mathrm{~nm}, 325 \mathrm{~nm}$ and $380 \mathrm{~nm}$ (Fig. 3c).

After the heat treatment, the excitation band at around $325 \mathrm{~nm}$ is blue shifted while a new strong excitation band appears, in relative intensity, at around $275 \mathrm{~nm}$. The excitation at around $380 \mathrm{~nm}$ is no longer present.

\section{Discussion}

\subsection{Phosphate glass irradiation and silver luminescent centers}

Despite the numerous works dedicated to the study of the photoluminescence of photosensitive glasses under various irradia tion (gamma, infrared), the luminescence mechanisms are not fully

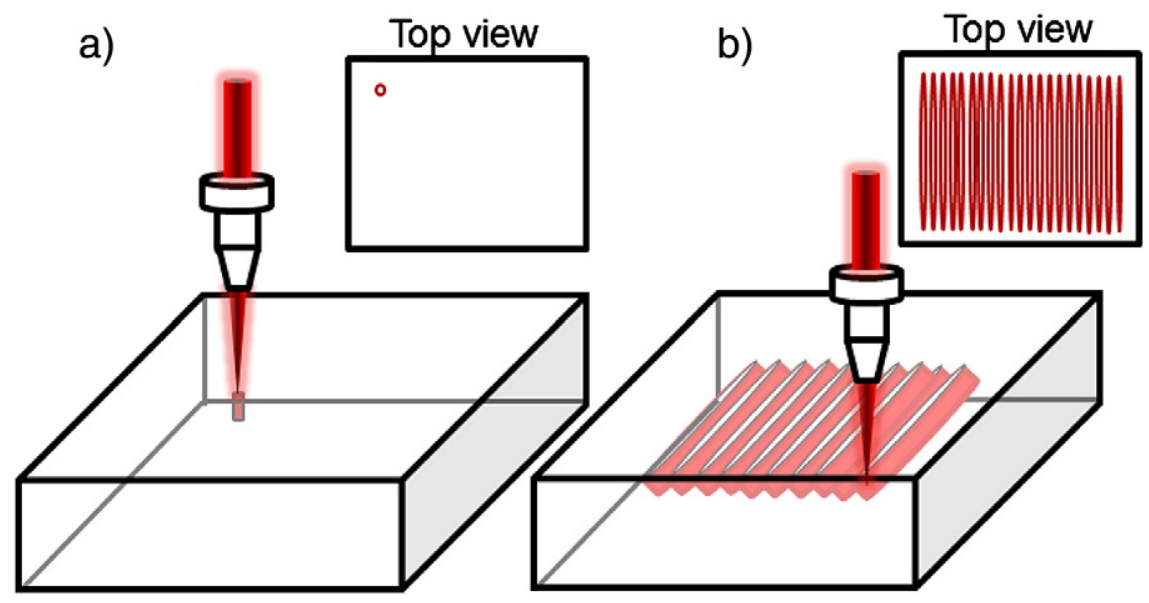

Fig. 1. a) Single structure and b) "squared" pattern composed of parallel lines induced by femtosecond direct laser writing within the photosensitive glass. 
a)

$(\mathrm{eV})$

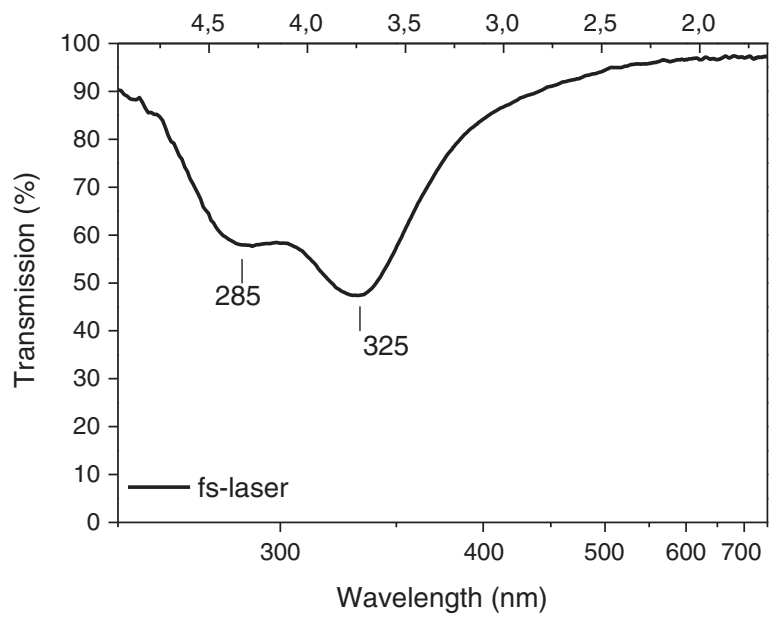

b)

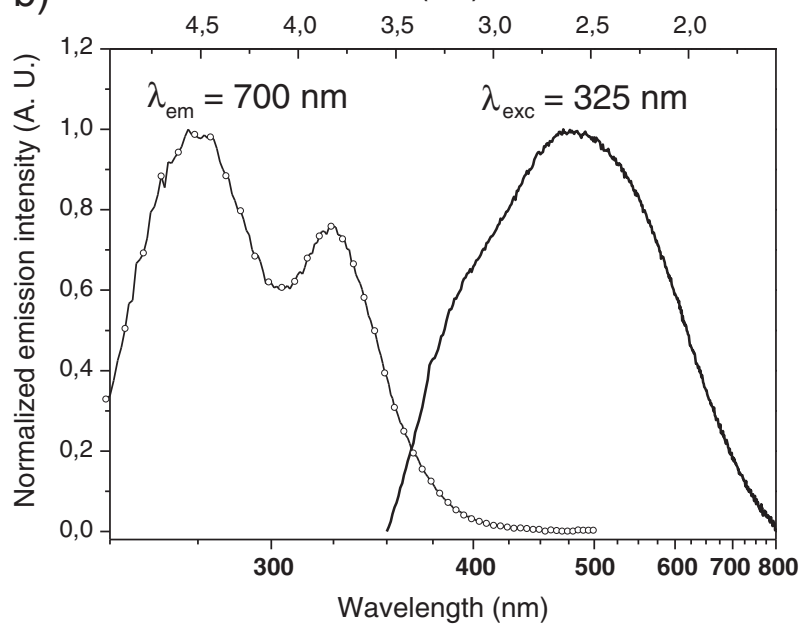

Fig. 2. a) Transmission and b) emission and excitation spectra of the squared pattern $\left(50 \times 50 \mu \mathrm{m}^{2}\right.$ area $)$ written by fs laser.

elucidated. An emission band from $560 \mathrm{~nm}$ up to $650 \mathrm{~nm}$ is obtained systematically by several authors in phosphate glass [17 23] under excitation in a wide spectral range between 270 and $400 \mathrm{~nm}$. The photo induced silver species are generally described as electron centers $\left(\mathrm{Ag}^{0}\right)$, hole centers $\left(\mathrm{Ag}^{2+}\right)$ or clusters $\left(\mathrm{Ag}_{\mathrm{m}}^{\mathrm{x}}\right)$. The $\mathrm{Ag}^{0}$ centers absorb in the $350500 \mathrm{~nm}$ range and are not luminescent [18,20,21]. The absorption of $\mathrm{Ag}^{2+}$ centers have been reported at between 280 and $310 \mathrm{~nm}$ and the emission is reported from 560 to $660 \mathrm{~nm}$ depending on the authors $[22,23]$. These species result from the transfer of a hole trapped on a phosphate group towards the $\mathrm{dx}^{2}-\mathrm{y}^{2}$ orbitals of an $\mathrm{Ag}^{+}$ion, absorbing at around $280 \mathrm{~nm}[18,20]$. The emission of $\mathrm{Ag}^{2+}$ centers is typical of defects close to phosphate groups [24,25]. $\mathrm{The}^{\mathrm{Ag}} \mathrm{g}_{\mathrm{m}}^{\mathrm{x}}$ clusters of low nuclearity (typically $\mathrm{Ag}_{2}^{+}$or $\mathrm{Ag}_{3}^{2+}$ ) absorb in the $270320 \mathrm{~nm}$ range [18,20,21]. The theoretical absorption character istics of various clusters were determined by Ershov et al. [26]. The authors calculated that the $\mathrm{Ag}^{2+}$ species have absorption features at around $310320 \mathrm{~nm}$ and $360400 \mathrm{~nm}$ and that the $\mathrm{Ag}_{3}^{2+}$ clusters ex hibit intense absorption bands near $260285 \mathrm{~nm}$ and $540720 \mathrm{~nm}$, and a lower one at $275320 \mathrm{~nm}$. However, no clear attribution of a spe cific luminescence has been provided up to now for such clusters [27 31].

We have conducted a systematic study combining EPR, optical ab sorption and luminescence spectroscopies to provide the assignment of the different absorption and luminescence features to the hole and the electron centers and to the clusters [32]. a) $(\mathrm{eV})$

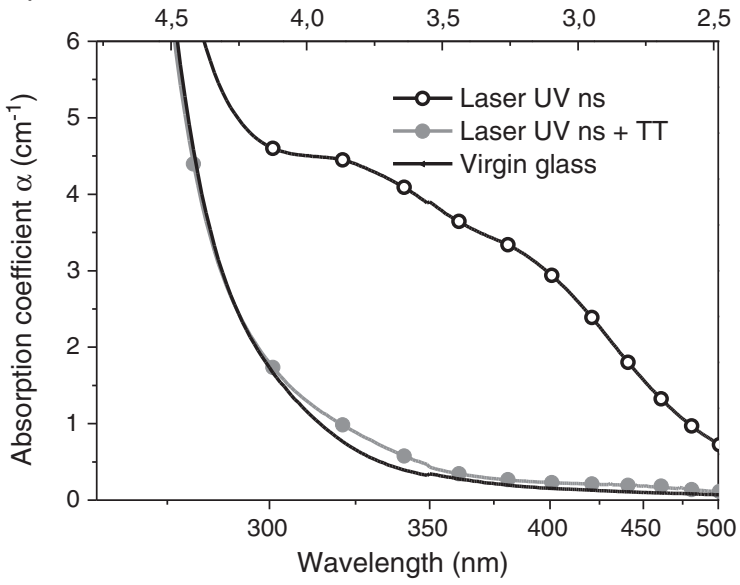

$(\mathrm{eV})$

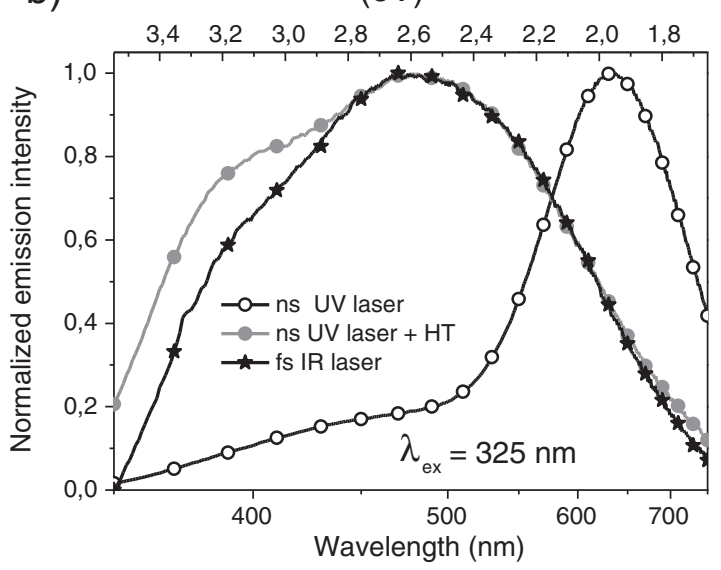

c) $(\mathrm{eV})$

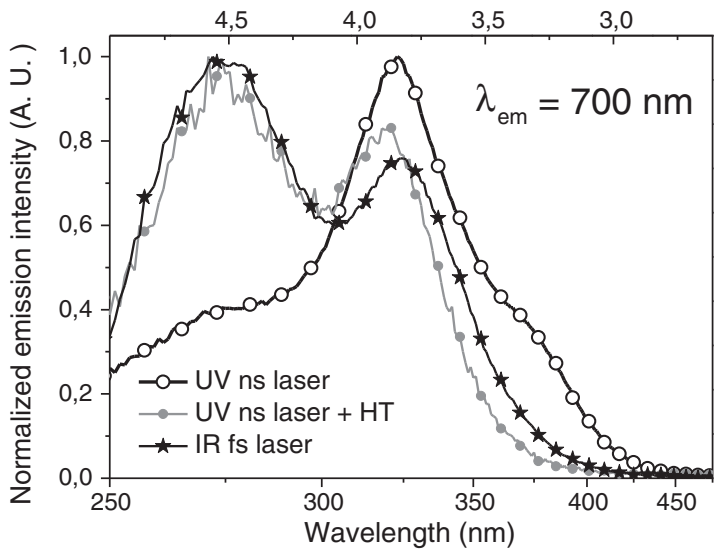

Fig. 3. a) Absorption spectra before, after ns-laser irradiation and after heat treatment $\left.\left(400{ }^{\circ} \mathrm{C}, 10 \mathrm{~min}\right), \mathrm{b}\right)$ emission spectra for $\lambda_{\mathrm{ex}}=325 \mathrm{~nm}$, and c) excitation spectra at $\lambda_{\mathrm{em}}=700 \mathrm{~nm}$ after ns-laser irradiation, after ns laser irradiation and heat treatment and after fs-laser irradiation.

\subsection{Ns laser irradiation}

After ns irradiation, absorption bands at 380 and $325 \mathrm{~nm}$ are ob served (Fig. 3a) and are attributed respectively to the $\mathrm{Ag}^{0}$ and to the $\mathrm{Ag}^{2+}$ centers. An excitation at $325 \mathrm{~nm}$ gives rise to a main emission band at around $630 \mathrm{~nm}$ (Fig. 3b). This emission band is attributed to the $\mathrm{Ag}^{2+}$ centers. Moreover, regarding the emission at $630 \mathrm{~nm}$ (Fig. 3d), the main excitation bands at $325 \mathrm{~nm}$ and the shoulders 
around $280 \mathrm{~nm}$ and $380 \mathrm{~nm}$ may be considered as directly connected to these centers.

\subsection{Ns laser irradiation followed by heat treatment}

After the heat treatment, the decrease of the intensity of the ab sorption spectrum, matching almost the absorption spectrum of the pristine glass, indicates that most of the species have disappeared (Fig. 3a). This decrease of the absorption spectrum is accompanied by a strong decrease of the emission band at $630 \mathrm{~nm}$ (Fig. 3b), related to the $\mathrm{Ag}^{2+}$ centers, and by the existence of a main emission at around $500 \mathrm{~nm}$, which are most probably attributable to small clus ters composed of a few silver atoms and ions such as $\mathrm{Ag}_{2}^{+}$or $\mathrm{Ag}_{3}^{\mathrm{n}+}$ [33,19].

The excitation spectrum also shows significant modifications. The excitation band at $380 \mathrm{~nm}$ has disappeared, indicating most likely the disappearance of $\mathrm{Ag}^{2+}$ species, as suggested by the absorption spec trum. The band at $325 \mathrm{~nm}$ is blue shifted and a main band in relative intensity is seen at $275 \mathrm{~nm}$. A cross analysis between the emission signatures at around $380 \mathrm{~nm}$ and $500 \mathrm{~nm}$, for an excitation at $325 \mathrm{~nm}$, and the excitation spectrum indicates that the formation of silver clusters is related to the thermal treatment above the glass transition temperature, which allows ionic and charge migrations.

Moreover after the thermal treatment, a lifetime of the excited state less than $10 \mathrm{~ns}$ is clearly measured as compared to a lifetime of about $8 \mu \mathrm{s}$ measured prior to thermal treatment. This measure ment is in accordance with the presence of silver clusters exhibiting large emission cross sections. Syutkin et al. assumed that the cluster formation was governed by the diffusion of $\mathrm{Ag}^{+}$ions [19,34], and re quires the transfer of an electron coming from a phosphate group to wards a $\mathrm{Ag}^{+}$ion to initiate the clustering reactions [34]. Even if the thermal treatment tends to show that the formation of silver clusters occurs, it is not possible to rule out the fact that clusters exist prior the thermal treatment. More investigations are necessary to separate the strong emission from the hole trapping centers $\mathrm{Ag}^{2+}$, and the emis sion from the silver clusters, if they are present.

\subsection{Comparison between the different irradiations}

The emission spectrum of the "squared" pattern written by fs laser (Fig. 3b) presenting two main bands at around $380 \mathrm{~nm}$ and $500 \mathrm{~nm}$ shows strong similarities with the ns UV laser irradiated and heat treated sample. The transmission spectrum in Fig. 2a shows two main bands at $285 \mathrm{~nm}$ and $325 \mathrm{~nm}$. The excitation spectra for an emission at $700 \mathrm{~nm}$ are also analogous with the ones of the heat treated sample after ns UV laser irradiation. The only clear difference is the shift of the band at around $325 \mathrm{~nm}$ for the ns UV laser irradiated and heat treated sample. Such effect could be related to the fact that in the heat treated sample, the hole trapping centers $\mathrm{Ag}^{2+}$ have most like ly completely disappeared, leading to the extinction of the shoulder at $380 \mathrm{~nm}$. The high repetition rate fs laser writing process leads to lumi nescent features comparable with ns UV laser irradiation followed by thermal treatment. The fs laser irradiation allows the formation of high concentrations of silver clusters, without significant resulting con centrations of unstable hole and electron traps such $\mathrm{as}^{\mathrm{Ag}} \mathrm{g}^{2+}$ and $\mathrm{Ag}^{0}$. This observation is in agreement with the stability of the fs laser induced luminescent structures through pulse after pulse heat accumu lation, and is an important aspect in terms of future possible applica tions, such as long term 3D optical data storage [35].

\section{Conclusions}

In conclusion, new insights for the identification of the lumines cent species induced by high repetition rate femtosecond laser in photosensitive silver containing glasses have been provided in this paper. The spectral (absorption, excitation and emission) properties of such structures have been characterized and compared to those of nanosecond laser irradiated samples after annealing at a tempera ture above the glass transition temperature. Analogous signatures have been pointed out, indicating that the femtosecond laser irradia tion combines the advantages of both the photo ionization and a local micrometric heat treatment in a one step procedure. The reported data bring new elements for the understanding of the remarkable sta bility of the photo induced structures through thermal treatments.

\section{Acknowledgments}

This work has been supported by the GIS "Advanced Materials in Aquitaine", the Region Aquitaine (grant no. 20111101013) and the ANR (grants BLAN 94603 and BLAN 946 04).

\section{References}

[1] M. Ams, G.D. Marshall, P. Dekker, J.A. Piper, M.J. Withford, Laser Photonics Rev. 3 (6) (2009) 535-544.

[2] A. Royon, Y. Petit, G. Papon, M. Richardson, L. Canioni, Opt. Mater. Express 1 (2011) 866.

[3] K. Tanaka, A. Saitoh, N. Terakado, J. Optoelectron. Adv. Mater. 8 (6) (2006) 2058-2065.

[4] E.N. Glezer, M. Milosavljevic, L. Huang, R.J. Finlay, T.-H. Her, J.P. Callan, E. Mazur, Opt. Express 21 (24) (2005) 2023.

[5] L. Canioni, M. Bellec, A. Royon, B. Bousquet, T. Cardinal, Opt. Lett. 33 (4) (2008) 360-362.

[6] K. Hirao, K. Miura, J. Non-Cryst. Solids 239 (1998) 91-95.

[7] A. Saliminia, R. Vallée, S.L. Chin, Opt. Commun. 256 (2005) 422-427.

[8] S.M. Eaton, H. Zhang, P.R. Herman, F. Yoshino, L. Shah, J. Bovatsek, A.I. Arai, Opt. Express 13 (12) (2005) 4708-4716.

[9] M. Shimizu, M. Sakakura, M. Ohnishi, Y. Shimotsuma, T. Nakaya, K. Miura, K. Hirao, J. Appl. Phys. 108 (2010) 073533.

[10] K. Miura, J. Qiu, T. Mitsuyu, K. Hirao, Opt. Lett. 25 (2000) 408.

[11] S. Kanehira, K. Miura, K. Hirao, Appl. Phys. Lett. 93 (2008) 023112.

[12] Y. Liu, B. Zhu, L. Wang, J. Qiu, Y. Dai, H. Ma, Appl. Phys. Lett. 92 (2008) 121113.

[13] C. Maurel, T. Cardinal, M. Bellec, L. Canioni, B. Bousquet, M. Treguer, J.J. Videau, J. Choi, M. Richardson, J. Lumin. 129 (12) (2009) 1514-1518.

[14] M. Bellec, A. Royon, B. Bousquet, K. Bourhis, M. Treguer, T. Cardinal, M. Richardson, L. Canioni, Opt. Express 17 (12) (2009) 10304-10318.

[15] K. Bourhis, A. Royon, M. Bellec, J. Choi, A. Fargues, M. Treguer, J.-J. Videau, D. Talaga, M. Richardson, T. Cardinal, L. Canioni, J. Non-Cryst. Solids 356 (2010) 2658-2665.

[16] M. Bellec, A. Royon, K. Bourhis, J. Choi, B. Bousquet, M. Treguer, T. Cardinal, J.-J. Videau, M. Richardson, L. Canioni, J. Phys. Chem. C 114 (37) (2010) 15584-15588.

[17] R. Yokota, H. Imagawa, J. Phys. Soc. Jpn. 23 (5) (1966) 1038-1048.

[18] T. Feldmann, A. Treinin, J. Chem. Phys. 47 (8) (1967) 2754-2758.

[19] V.M. Syutkin, A.B. Astashkin, A.V. Dmitryuk, Fiz. Khim. Stekla 18 (1) (1992) 139-148.

[20] D. Möncke, D. Ehrt, Opt. Mater. 25 (2004) 425-437.

[21] R. Espiau de Lamaestre, H. Béa, H. Bernas, J. Belloni, J.L. Marignier, Phys. Rev. B 76 (2007) 205431.

[22] S.M. Hsu, S.W. Yung, R.K. Brow, W.L. Hsu, C.C. Lu, F.B. Wu, S.H. Ching, Mater. Chem. Phys. 123 (2010) 172-176.

[23] Y. Miyamoto, Y. Takei, H. Nanto, T. Kurobori, A. Konnai, T. Yanagida, A. Yoshikawa, Y. Shimotsuma, M. Sakakura, K. Miura, K. Hirao, Y. Nagashima, T. Yamamoto, Radiat. Meas. 45 (2010) 546-549.

[24] L.B. Fletcher, J.J. Witcher, N. Troy, S.T. Reis, R.K. Brow, D.M. Krol, Opt. Express 19 (9) (2011) 7929-7936.

[25] L.B. Fletcher, J.J. Witcher, N. Troy, S.T. Reis, R.K. Brow, R.M. Vazquez, R. Osellame, D.M. Krol, Opt. Mater. Express 1 (5) (2011) 845-855.

[26] B.G. Ershov, G.V. Ionova, A.A. Kiseleva, Russ. J. Phys. Chem. 69 (2) (1995) 239-248.

[27] G. De Cremer, Y. Antoku, M.B.J. Roeffaers, M. Sliwa, J. Van Noyen, S. Smout, J. Hofkens, D.E. De Vos, B.F. Sels, T. Vosch, Angew. Chem. Int. Ed. 47 (2008) 2813

[28] G. De Cremer, B.F. Sels, J.-I. Hotta, M.B.J. Roeffaers, E. Bartholomeeusen, E. Coutino-Gonzales, V. Valtchev, D.E. De Vos, T. Vosch, J. Hofkens, Adv. Mater. 22 (2010) 957.

[29] G. De Cremer, E. Coutiño-Gonzalez, M.B.J. Roeffaers, B. Moens, J. Ollevier, M. Van der Auweraer, R. Schoonheydt, P.A. Jacobs, F.C. De Schryver, J. Hofkens, D.E. De Vos, B.F. Sels, T. Vosch, J. Am. Chem. Soc. 131 (2009) 3049.

[30] F. Fayazpour, B. Lucas, N. Huyghebaert, K. Braeckmans, S. Derveaux, B.G. Stubbe, J.-P. Remon, J. Demeester, C. Vervaet, S.C. De Smedt, Adv. Mater. 19 (2007) 3854.

[31] L.A. Peyser, A.E. Vinson, A.P. Bartko, R.M. Dickson, Science 291 (2001) 103.

[32] K. Bourhis, A. Royon, G. Papon, M. Bellec, Y. Petit, L. Canioni, M. Dussauze, V. Rodriguez, L. Binet, D. Caurant, M. Treguer, J.J. Videau, T. Cardinal, Materials Research Bulletin, article accepted.

[33] I. Belharouak, C. Parent, B. Tanguy, G. Le Flem, M. Couzy, J. Non-Cryst. Solids 244 (2-3) (1999) 238-249.

[34] V.M. Syutkin, A.V. Dmitryuk, V.A. Tolkachev, Fiz. Khim. Stekla 18 (3) (1992) 66-76.

[35] A. Royon, K. Bourhis, M. Bellec, G. Papon, B. Bousquet, Y. Deshayes, T. Cardinal, L. Canioni, Adv. Mater. 22 (46) (2010) 5282-5286. 